\title{
APONTAMENTOS SOBRE A CONCEPÇÃO FENOMENOLÓGICA DO "SE- MOVIMENTAR” NA EDUCAÇÃO FÍSICA ESCOLAR: UMA CRÍTICA ELUCIDADA PELA PEDAGOGIA HISTÓRICO-CRÍTICA
}

\author{
Matheus Bernardo Silva, \\ Lígia Regina Klein \\ Universidade Federal do Paraná - UFPR
}

\section{RESUMO}

O objetivo desse artigo é explicitar criticamente os fundamentos da tendência teóricometodológica específica da educação física escolar denominada "crítico-emancipatória" que tem entre os seus embasamentos teóricos a fenomenologia. Essa tendência se propõe a explicar o objeto de conhecimento da educação física escolar, isto é, a "cultura de movimento" seguindo as orientações filosóficas da concepção fenomenológica do "semovimentar" e, dessa forma, busca expor uma reflexão crítica frente os elementos específicos da educação física. Confrontando com essa perspectiva, procuramos explicitar: 1) a impossibilidade de compreender o objeto de conhecimento da educação física escolar e de propor uma reflexão e intervenção crítica tendo como embasamento filosófico a fenomenologia; 2) apontamos, então, como proposição os fundamentos da pedagogia histórico-crítica em proveito de compreender a relação do objeto de conhecimento da educação física escolar com a sua função social perante a formação humana. Pontuamos elementos concretos da pedagogia histórico-crítica que, em nossa compreensão, possam contribuir para uma reflexão e intervenção em um âmbito pedagógico crítico.

Palavras-chave: Educação Física Escolar; Concepção Fenomenológica do "SeMovimentar"; Pedagogia Histórico-Crítica.

\section{NOTES ON THE PHENOMENOLOGICAL CONCEPTION OF "IF-MOVE" ON SCHOOL PHYSICAL EDUCATION: A CRITIQUE UNDERSTOOD BY HISTORICAL-CRITICAL PEDAGOGY}

\begin{abstract}
The aim of this article is to clarify the foundations of theoretical trend critically-specific methodology of school physical education named "critical-emancipatory" which has among its theoretical ramming the Phenomenology. This trend sets out to explain the object of knowledge of school physical education, that is, the "culture of movement" following the guidelines of the phenomenological conception of philosophical "If-move" and, thus, seeks to expose a critical reflection on the specific elements of the physical education. Confronting with this perspective, we seek to clarify: 1) the impossibility of understanding the knowledge object of school physical education and to propose a reflection and critical intervention having as basis the philosophical phenomenology; 2) aim, then, as proposition the fundamentals of historical-critical pedagogy for the benefit of understanding the relationship of the object of knowledge of school physical education with their social function in the human formation. Score concrete elements of historicalcritical pedagogy, in our understanding, contribute to reflection and intervention in a critical pedagogical context.

Keywords: School Physical Education; Phenomenological Conception of "If-Move"; Historical-Critical Pedagogy.
\end{abstract}




\section{Considerações iniciais}

Atualmente no cenário brasileiro existe uma série de elementos que estão em voga no bojo da reflexão sobre o objeto de conhecimento da educação física escolar.

Persistem, ainda, as proposições embasadas pelos pressupostos positivistas que compreendem a educação física escolar como um componente curricular que deve fomentar e intervir na formação do indivíduo por meio das "valências" físicas, da aptidão física, em tese, em proveito de uma análise descontextualizada histórica e socialmente, caracterizando apenas as condições biológicas ("naturalizantes") do indivíduo. Reduzindo, então, as intervenções por condicionantes invariáveis, procurando diagnosticar o indivíduo por uma feição individual inerente daquele sujeito, como se fosse possível realmente compreendermos a formação humana por meio apenas dos indivíduos "individuais", sem a sua relação com o meio circundante e com os demais indivíduos. "A definição clássica de $\mathrm{EF}^{1}$, nessa perspectiva, é a que a considera como disciplina que, por meio das atividades físicas, promove a educação integral do ser humano - mas, a conotação, na prática, é a do desenvolvimento físico-motor ou da aptidão física (...).” (BRACHT, 2007, p. 43).

Em outra vertente, existem proposições que caminham para uma compreensão do objeto de conhecimento da educação física escolar como sendo o "movimento humano" subsidiado pelas diretrizes comportamentais, isto é, pela reflexão sob a égide da aprendizagem motora do desenvolvimento humano. Há no discurso dessas perspectivas que a educação física escolar por meio da intervenção via a aprendizagem motora é capaz de contribuir para a formação integral do indivíduo. "A definição clássica, nesse caso, é a de que a EF é a educação do e pelo movimento." (idem, p. 44, itálicos no original).

As duas definições - a biológica e a desenvolvimentista, respectivamente - que citamos conduzem a reflexão sobre o objeto de conhecimento da educação física escolar para uma recusa desse objeto como construção histórica e social, ou seja, não considerando como o principal critério de análise a prática social.

Contudo, não explicitaremos com maiores detalhes essas teorizações supracitadas a respeito do objeto de conhecimento da educação física escolar. Iremos a partir desse momento apresentar e averiguar criticamente uma teorização que se encontra muito presente no campo de discussões da educação física escolar sobre o seu objeto de conhecimento. Entretanto, essa teorização parte para uma compreensão de que o objeto de conhecimento da educação física escolar está no âmago dos condicionantes provenientes da cultura.

No entanto, no interior dessa teorização existem incoerências no âmbito conceitual de compreender o "real" objeto de conhecimento da educação física escolar em consonância com sua a função social. Essas incoerências ocorrem pelo fato de que a mesma adota referências de cunho filosófico, ontológico, epistemológico que não conseguem explicitar de forma coesa as ações humanas no seu meio circundante. Nesse sentido, daremos ênfase na tendência teórico-metodológica voltada para a educação física escolar intitulada "crítico-emancipatória" que possui entre os seus embasamentos teóricos a concepção fenomenológica do "se-movimentar" propor que o objeto de conhecimento da educação física escolar é "a cultura de movimento".

Situando essa tendência historicamente, mencionamos que na década de 1990, no Brasil, surge um estudo sobre as orientações de cunho teórico-metodológica para educação física escolar que parte para um entendimento da ontologia do movimento humano baseado na concepção fenomenológica do "se-movimentar". Elenor Kunz² (2000; 2004; 2006a; 2006b) é o principal autor no Brasil que designou os seus estudos para aprofundar essa 
teorização sobre a educação física escolar. Os fundamentos utilizados pela a tendência crítico-emancipatória pode ser encontrada mais precisamente na "didática comunicativa" que sofre influência de Habermas; das orientações de Paulo freire e; principalmente, da filosofia fenomenológica como orientação para compreender o movimento humano oriundo da cultura de movimento.

Kunz (2006b, p. 13) efetiva sua justificativa e defesa dos pressupostos da tendência crítico-emancipatória em proveito de um ensino que tenha como intuito " (...) esclarecer as razões e as necessidades de introduzir, na escola, uma nova forma de tematizar o ensino, neste caso, o ensino do movimento humano (...)."

É nesse intento que iremos enfocar o nosso trabalho: 1) dando ênfase primeiramente nas proposições da tendência crítico-emancipatória com o objetivo de averiguar criticamente a reflexão sobre a cultura de movimento com base na concepção fenomenológica do se-movimentar; 2) em seguida iremos nos reportar para a nossa compreensão da educação física escolar e a sua função social tendo como fio condutor os fundamentos da pedagogia histórico-crítica.

Procuramos, assim, expor por meio desse trabalho que há a necessidade de termos como horizonte a cultura como sustento do objeto de conhecimento da educação física. Entretanto, a compreensão que devemos ter como cultura se dá por meio da produção social. Contudo, a tendência crítico-emancipatória não apresenta elementos concretos para a intervenção pedagógica no sentido de transmitir o conhecimento na sua forma mais elaborada que foi e é construído histórica e socialmente pela a humanidade em prol de uma reflexão pedagógica crítica e que perspective um possível projeto histórico superador.

A justificativa de darmos enfoque na compreensão de Kunz sobre a relação do indivíduo com o meio circundante se faz, porque compreendemos que há embasamentos contraditórios intrínsecos na tendência crítico-emancipatória que não permitem o estudo e a análise da totalidade e da concreticidade da realidade social. Essas determinações são necessárias para a compreensão da relação indivíduo e o seu meio circundante e, no recorte desse trabalho, do objeto de conhecimento da educação física escolar no que tange a sua função social. A necessidade de darmos ênfase na discussão sobre a tendência teóricometodológica crítico-emancipatória se dá pela sua atualidade tanto no campo acadêmico como no escolar no bojo da educação física a nível nacional, conforme afirmam Ortigara e Bernardo Silva (2011).

A análise que efetivamos no decorrer do trabalho para a investigação dos elementos constituintes da tendência crítico-emancipatória está fundamentada, principalmente, nas categorias de "historicidade" e da "totalidade", pois nos permitem avaliar determinações que regem o movimento da realidade social e, portanto, do movimento humano. Alves (2006, p. 10), baseado no materialismo histórico-dialético, esclarece que essas categorias não são exclusivas, mas no momento que são tomadas para uma análise, ambas permitem "(...) a explicitação de aspectos importantes do tratamento teórico-metodológico dado ao objeto." A nossa intenção é ter sob "os nossos próprios pés" os condicionantes sociais que influenciam no âmbito escolar e, dessa maneira, na especificidade da educação física escolar. O que estamos mencionando é que há a necessidade de analisar a complexidade da realidade social por base na materialidade da totalidade concreta. Nesse sentido, Kosik (2010, p. 41) afirma que "Do ponto de vista da totalidade, compreende-se a dialética da lei e da causalidade dos fenômenos, da essência interna e dos aspectos fenomênicos da realidade, das partes e do todo, do produto e da produção e assim por diante."

$\mathrm{Na}$ sequência aprofundamos o debate sobre a concepção fenomenológica do semovimentar no sentido de investigar a influência que essa concepção exerce no seio da 
tendência crítico-emancipatória para interpretar e fundamentar uma ótica sobre objeto de conhecimento da educação física escolar e da sua organização pedagógica.

\section{A cultura de movimento e a concepção fenomenológica do "se-movimentar"}

A discussão sobre o movimento humano, diz Kunz (2004), é uma questão que é sempre relacionada com a reflexão sobre o corpo ou a corporeidade. Destarte, o autor efetiva a crítica e a necessidade de superação dos conceitos dualistas entre corpo e espírito. Argumenta-se pela a necessidade de haver novos conceitos para poder definir o corpo como sujeito em relação com o meio social.

Expressa-se no âmbito da tendência crítico-emancipatória uma crítica a compreensão do movimento humano por: 1) meio dos princípios de competição e concorrência, muito presente nas proposições de cunho positivista; 2) meio do movimento humano tendo enfoque apenas nas maneiras "corretas" de realizar certo movimento; 3) meio do enfoque unicamente da qualidade e quantidade da realização de determinados movimentos, no sentido de atingir o auge da performance técnica e física e/ou para a "melhora da qualidade vida"; 4) meio de explicitações voltadas apenas para atividades "lúdicas" que não possuem um sentido histórico-social para os indivíduos.

Dado as críticas aos processos conservadores que fomentam a educação física escolar via as perspectivas que mencionamos acima, Kunz (2006b) sustenta a sua concepção de movimento humano, como já afirmamos, na filosofia fenomenológica. Assim o autor define que "O homem como um "ser-no-mundo" é sempre a presença de um corpo fenomenológico, na concepção de Merleau-Ponty (1966). Nesse conceito de corpo o pensar é tão corporal como o correr (...).” (idem, p. 20, itálicos no original).

Por essa contextualização, Kunz (2006a) menciona que o objeto central da educação física escolar, de acordo com a tendência crítico-emancipatória é o "semovimentar" humano. A relação entre o ser humano e o mundo se dá por meio de sentidos e significados que ocorrem via o movimentar-se, numa dada determinação estética que é caracterizado como um "se-movimentar". Conforme salienta Kunz (idem, p. 27):

O movimento humano, como um "se-movimentar", é um fenômeno relacional de "Ser Humano-Mundo", e caracteriza-se, sempre, como uma espécie de "diálogo". Uma de nossas melhores linguagens de relacionamento nos diferentes contextos socioculturais, portanto, realizase via movimento. A exploração e o desenvolvimento dessa linguagem abrem horizontes imprevisíveis e impressionantes, especialmente entre crianças e jovens, na vida de relações não apenas profissionais, mas especialmente afetivas, emocionais e de sensibilidade com a natureza e a cultura.

Fundamentado ainda nos elementos da filosofia fenomenológica, Kunz (idem) explicita fundamentos sob a égide da tendência crítico-emancipatória com base nos estudos dos holandeses ${ }^{3}$ Gordijn, Bytendijk e Tamboer e também nas orientações do alemão Trebels $^{4}$, a fim de, estudar o acúmulo teórico desenvolvido por tais autores referente às diferentes formas de "existência" do movimento humano.

Kunz (2000) menciona que o movimento humano na concepção do "semovimentar" deve referir-se a no mínimo três dimensões ao "se-movimentar dos indivíduos": 1) o ator como sujeito das ações; 2) as ações do movimento estão ligadas a uma situação concreta; 3) há sempre um significado que está orientando as ações do 
movimento que acaba se tornando o responsável pela a apreensão da estrutura proveniente de tais ações.

"O movimento humano, nesta perspectiva do se-movimentar, é entendido como uma conduta de atores numa referência sempre pessoal-situacional. Portanto, isso só pode ser um acontecimento relacional, dialógico." (idem, p. 03). Por isso, é evidenciado que a concepção do "se-movimentar" deve sempre estar intimamente relacionada com a relação dialógica do ser humano. Portanto, para que se constitua uma unidade dialógica do movimentar-se é levado em consideração a categoria "intencionalidade" que, refere-se as relações dialógicas entre sujeito-objeto e vice-versa. Essas relações podem ocorrer em distintas maneiras como: na forma afetiva, pensada, emocional, movimentando-se, etc. Trebels (2006, p. 41) explica que

Intencionalidade, para a Fenomenologia, não significa apenas, o ser humano dirigir a atenção a um objeto, mas, também, estar atento de forma pré-consciente e pré-relacional, tal como pode ser observado em organismos biológicos, pois ela é um sinal da vida. Por isso, é possível se referir à relação dialógica do ser humano que se movimenta, de uma mútua intencionalidade, ou seja, da intenção do mundo sobre o ator de movimentos e vice-versa. O mundo dos objetos fixos e seguros, pelas definições físicas, perde sua identidade e passividade no ato de se movimentar. Esta é uma das consequências, se levarmos a sério a concepção dialógica do movimento humano.

O "se-movimentar" significa - levando em consideração o posicionamento de Trebels - as atualizações dos significados motores dado as necessidades concretas que surgem e, que via os movimentos são realizados pelas possibilidades individuais ocorrem. Assim, no âmbito pedagógico, esse processo dialógico em relação ao "se-movimentar" deve ocorrer por meio de ações individuais dos alunos, isto é, por meio "(...) da espontaneidade e da autonomia individual (...). Esta responsabilidade e esta autonomia permitem às pessoas, constantemente, modificar e reestruturar as situações e significações dos movimentos." (KUNZ, 2000, p. 05).

Partindo da argumentação fenomenológica da relação sujeito-mundo, Kunz atribui o movimento humano como um fenômeno de extrema importância para a vida social de cada ser humano. O movimento, assim, na concepção de Kunz é a constituição de “(...) um meio e uma precondição para as experiências objetivas na vida de pessoas. Na perspectiva de um 'se-movimentar', a conduta dos sujeitos em ação deve ser realizada como um acontecimento relacional numa referência situacional-pessoal." (ARAÚJO et al., 2010, p. 02).

Na exposição que Kunz realiza com Araújo em mais outros autores é explícito a compreensão da relação do sujeito-mundo de uma maneira primeiramente individual (espontânea), isto é, partindo das premissas do indivíduo dadas as suas sensações com o mundo empírico/perceptível ou - na nomenclatura de Kunz - com o "mundo vivido" de cada um. Assim os autores explicitam que

um melhor entendimento do "se-movimentar" humano pode ser encontrado nos estudos acerca do "movimento próprio", descoberto no significado existencial do agir, na própria espontaneidade. Trata-se da relação sujeito-mundo e das relações de seres humanos nas dimensões espaço-temporais. (...) É preciso encontrar a "unidade primordial" (Merleau-Ponty, 1999) de um "ser-estar-no-mundo". (ARAÚJO et al., 2010, p. 02). 
Referente a essa "unidade primordial", a tendência crítico-emancipatória busca identificar-se com "(...) uma teoria não mecânica do movimento com a qual buscou resgatar o sentido do 'sujeito ativo', marcando uma forte diferença entre o ser humano como objeto e como sujeito do movimento." (ARAÚJO et al., 2010, p. 05). Portanto, seguindo as diretrizes dessa tendência, o "se-movimentar" possui diversas maneiras nas quais a unidade primordial dos indivíduos é se relacionar com o mundo.

Para refletir sobre essa relação dos indivíduos com o mundo, a categoria "linguagem" ganha um valor importante, principalmente, no que diz respeito a compreensão da tendência crítico-emancipatória sobre as determinações do ensino. Para essa tendência, a linguagem não só é verbal, mas no âmago da educação Física escolar se manifesta como um "ser-corporal" dos indivíduos, ou seja, nas palavras de Kunz (2006a, p. 37) é “( ...) a linguagem do 'se-movimentar' enquanto diálogo com o mundo."

Seguindo nas orientações do diálogo com o mundo, ou melhor, nesse caso, especificamente com a "linguagem do se-movimentar", a tendência crítico-emancipatória apresenta uma explicitação sobre o conhecimento que caracterizamos primordial para analisarmos a organização pedagógica de acordo com os seus fundamentos. O movimento humano, então, com base na concepção do "se-movimentar"

nasce das relações, do diálogo, da intersubjetividade numa perspectiva dinâmica, e as significações feitas são baseadas nos contextos que se apresentam e se modificam, momento a momento, deixando de lado a ideia de que o conhecimento está fundado numa coisa em si, seja ela a consciência ou um objeto. (ARAÚJO et al., 2010, p. 10).

Com o intuito de teorizar sobre a sua concepção de organização pedagógica, Kunz (2006b) expõe que todo o ato educativo é síntese de um processo que desenvolve a todo o momento ações comunicativas. Caracteriza-se no processo de ensino o aluno como o sujeito inserido na vida social e cultural. Priorizando, assim, a capacidade de fazer com que o aluno tenha a possibilidade de conhecer, reconhecer e propor problemáticas à luz dos sentidos e significados da vida social e cultural e, dessa forma, possa perspectivar a reflexão a partir de um posicionamento crítico. "O ensino deve fomentar, para tanto, a capacitação dos alunos para um agir solidário, nos princípios da codeterminação e autodeterminação." (KUNZ, 2006b, p. 37). A interação entre aluno-aluno e alunoprofessor deve ocorrer por meio da linguagem, isto é, a linguagem nesse caso é considerada como uma mediação simbólica.

Neste sentido, é pela interação e pela linguagem que o conhecimento técnico, cultural e social do (...) [movimento humano] é compreendido sem ser "imposto" de fora, e na "transformação didática" devem ser respeitados os conteúdos do "mundo vivido" dos participantes para que as condições de um entendimento racional, que se dá no nível comunicativo da intersubjetividade, possa ser alcançado. (KUNZ, 2006b, p. 37-38).

$\mathrm{Na}$ tentativa de excluir as antigas orientações dicotômicas da organização pedagógica sobre o objeto de conhecimento da Educação Física escolar, a tendência crítico-emancipatória apoia seus posicionamentos na condição da fenomenologia de não separar os indivíduos do mundo ou do seu meio circundante. Dessa forma, finalizamos a nossa exposição com a afirmação de Trebels no que se refere a assentar a concepção do "se-movimentar" por meio das orientações fenomenológicas na busca de apresentar a 
função do indivíduo enquanto um "ser-no-mundo": "Ser-movimentar é a forma de agir original do ser humano por meio da qual ele se garante como ser no mundo e na qual neste agir - ele mesmo, como sujeito, e o mundo, como sua contraface imaginária, adquirem contornos visíveis." (TREBELS, 2006, p. 40, itálicos no original).

Interpretamos essa afirmação como uma inflexão no que tange a compreensão da realidade social, ou seja, da compreensão do indivíduo como um ser que modifica e é modificado por meio das relações entre o mesmo e a natureza, e entre os próprios indivíduos. Caracterizamos ainda a tendência crítico-emancipatória por meio da sua compreensão fenomenológica do se-movimentar como explicação para o movimento humano - para a cultura de movimento - insuficiente perante a compreensão das diversas determinações que regem a totalidade concreta da realidade social, afinal, a sociedade é um "complexo de complexos". Afirmamos que, por meio da fundamentação da tendência crítico-emancipatória se torna impossível à análise de uma maneira crítica dos condicionantes da vida social e cultural que os indivíduos estão inseridos.

No próximo momento do nosso trabalho apresentamos elementos para contrapor esse posicionamento fundado na fenomenologia que tem como perspectiva a intervenção pedagógica incitada pelas ações individuais, isto é, parte-se da compreensão de que os atos dos indivíduos ganham efetividade no pensamento por meio da apropriação imediata do objeto. (ORTIGARA; BERNARDO SILVA, 2011). Como proposição, explicitaremos os fundamentos da pedagogia histórico-crítica com o objetivo de embasar a reflexão do objeto de conhecimento da educação física escolar e de sua organização pedagógica para que a mesma possa contribuir levando em consideração a sua especificidade em um posicionamento crítico. Buscamos, então, ir para além da compreensão da relação do indivíduo com o seu meio como uma elaboração subjetiva imediatista da realidade social.

\section{Contrapontos da pedagogia histórico-crítica frente à concepção fenomenológica do "se-movimentar"}

Como estudamos no decorrer dessa exposição, a concepção do "se-movimentar", de acordo com as exemplificações da tendência crítico-emancipatória e mais precisamente dos acúmulos teóricos de Kunz, parte de uma fundamentação filosófica da fenomenologia. $\mathrm{O}$ autor faz uma discussão baseado em tal aporte filosófico para apontar a relação entre sujeito-mundo que interpretamos como uma compreensão subjetiva imediata da realidade social, ou seja, as ações da realidade humana como "contraface imaginário" - nas palavras de Trebels (2006) - do mundo.

Dessa forma, inicialmente, mencionaremos o caráter fenomenológico utilizado pela tendência crítico-emancipatória. Pontuamos que a fenomenologia avulta e prioriza o caráter intencional da consciência. Segundo Abbagnano (2007, p. 511-512, itálicos no original) para a fenomenologia "(...) a consciência é um movimento de transcendência em direção ao objeto e o objeto se dá ou se apresenta à consciência 'em carne e osso' ou 'pessoalmente' (...)." (ABBAGNANO, 2007, p. 511-512, itálicos no original).

Seguindo, ainda, as contribuições de Abbagnano (idem, p. 512, itálicos no original) mencionamos que

A formulação fenomenológica da filosofia não implica, portanto, a redução da existência à aparência e não pode ser confundida de maneira nenhuma com o fenomenismo (...). Por outro lado, tampouco implica a eliminação da diferença entre parecer e ser, embora esse antigo dualismo 
seja eliminado. (...) A relação entre aparência e ser, na ontologia fenomenológica, pode ser definida ou analisada de maneiras diferentes, mas não se molda à tradição que relaciona aparência e realidade.

Os fenômenos para a fenomenologia já possui a "coisa em si”. Podemos resumir a fenomenologia perante o movimento que o indivíduo se volta para as coisas, isto é, para o seu "mundo vivido" e o descreve da maneira que aparece na consciência na sua forma imediata. Isto significa, de acordo com Saviani (2012a), que o modo do indivíduo "ser-nomundo" se dá pela captação de forma imediata do objeto; o que está preenchendo a consciência são as condições externa a ela, ou seja, o mundo. A relação entre indivíduo e mundo ocorre por meio de uma simples apropriação da consciência do "mundo dado".

Conforme Saviani (2012a, p. 159, itálicos no original) "Essa atitude é possível em virtude da intencionalidade da consciência." Quando se volta para os fenômenos, a consciência procede por meio de reduções sucessivas. Ocorre a tentativa de descrição dos fenômenos para tentar capturar a sua essência. Compreende-se que a interpretação dos dados da realidade concreta surge de maneira intencional na consciência humana.

Percebemos com base nessa análise que se torna impossível atender a um dos preceitos elencados por Kunz no que tange a função social da educação física escolar, ou seja, no seio da cultura de movimento, fundamentado pela concepção fenomenológica do "se-movimentar", enfocar na intervenção pedagógica em que

O aluno enquanto sujeito do processo de ensino deve ser capacitado para sua participação na vida social, cultural e esportiva, o que significa não somente a aquisição de uma capacidade de ação funcional, mas a capacidade de conhecer, reconhecer e problematizar sentidos e significados nesta vida, através da reflexão crítica. (KUNZ, 2006a, p. 31).

A impossibilidade se dá de atuar em proveito de uma reflexão crítica, dada às fundamentações filosóficas da fenomenologia, pois a mesma em momento algum se interessa em apreender os dados da realidade concreta por meio de uma compreensão da historicidade dos fenômenos. (TRIVIÑOS, 2009). No caso, da especificidade da concepção fenomenológica do "se-movimentar", é irreal a compreensão da totalidade do movimento humano. Conduzindo a reflexão sobre o objeto de conhecimento da educação física e da sua organização pedagógica por determinações anistóricas, não dialéticas e cadenciando, então, para uma compreensão conservadora da realidade social.

Saviani (2012a, p. 159-160) afirma que

Nessa perspectiva, o ato educativo é entendido como possibilitando a abertura das consciências para o mundo, empenhando-se os alunos em compreender o sentido dos fenômenos constitutivos do mundo vivido, exercitando, para isso, sua capacidade de operar reduções. Aprenderão, diante de determinado problema, a colocar entre parêntesis as opiniões corretas, as crenças, os preconceitos e, até mesmo, as teorias já formuladas começando pela análise direta dos fenômenos implicados no enunciado do problema que se quer esclarecer.

Esse movimento unicamente empírico em relação à abstração dos dados da realidade concreta induz o indivíduo apenas a apreender os fatos e "viver" sob uma práxis utilitária, isto é, “(...) a praxis (sic.) fragmentária dos indivíduos, baseada na divisão do trabalho, na divisão da sociedade em classes e na hierarquia de posições sociais que sobre ela se ergue.” (KOSIK, 2010, p. 14, itálicos no original). 
A reflexão pedagógica com base nos fenomenológicos conduzem a investigação e intervenção pedagógica para que apenas haja um "esclarecimento" sobre os condicionantes sociais e, esse "esclarecimento" ocorre ainda de maneira distorcida entre a subjetividade do indivíduo com a imagem do real. Dessa maneira, há a exclusão intencional ou não dos conflitos entre as classes sociais, pois limitam a realidade concreta apenas para as compreensões dos fenômenos empíricos, não conseguindo atingir a essência dos movimentos oriundos do modo de produção hodierno. Sendo assim, tal proposição caminha mesmo não afirmando explicitamente esse posicionamento para a manutenção do status quo. Hipertrofiando a "subjetividade objetiva" dos indivíduos.

Não há, portanto, por meio desses pressupostos a concepção de "(...) Homem que vive numa dada sociedade num dado momento histórico determinado por uma configuração social e por um desenvolvimento material concreto e, por isso, com determinadas e específicas exigências no plano educativo." (ESCOBAR, 1995, p. 92, itálico no original).

Partindo de uma crítica aos moldes fenomenológicos de compreender o movimento humano e, dessa maneira, de apresentar elementos pedagógicos para a reflexão e intervenção na educação física escolar, concebemos os pressupostos da pedagogia histórico-crítica como embasamento capaz de contribuir com a especificidade da educação física escolar e, com isso, poder propor uma intervenção realmente crítica frente o modo de produção capitalista.

Portanto, antes de entrarmos especificamente na contribuição da pedagogia histórico-crítica, mencionamos que no campo da educação física escolar existe uma reflexão que parte também, assim como a pedagogia histórico-crítica, dos pressupostos filosóficos, ontológicos e epistemológicos do materialismo histórico-dialético. Tal tendência teórico-metodológica se intitula "crítico-superadora" (COLETIVO DE AUTORES, 1992) e caracteriza como objeto de conhecimento da Educação Física escolar, a cultura corporal. De acordo com o Coletivo de Autores (1992, p. 38)

$\mathrm{Na}$ perspectiva da reflexão sobre a cultura corporal, a dinâmica curricular, no âmbito da Educação Física (...) Busca desenvolver uma reflexão pedagógica sobre o acervo de formas de representação do mundo que o homem tem produzido no decorrer da história, exteriorizadas pela expressão corporal: jogos, danças, lutas, exercícios ginásticos, esporte, malabarismo, contorcionismo, mímica e outros, que pode ser identificados como formas de representação simbólica de realidade vividas pelo homem, historicamente criadas e culturalmente desenvolvidas.

Escobar (1995) afirma que a tendência crítico-superadora busca estar inserida em um projeto histórico superador. Tal tendência, então, apresenta elementos de cunho pedagógico tendo como grande premissa a crítica radical ao modo de produção capitalista. Por essa contextualização, a tendência crítico-superadora tem como concepção do objeto de conhecimento da Educação Física escolar, a cultura corporal, como produção social que os indivíduos atuando em sociedade produziram no decorrer da história que devem ser transmitidos para as sucessivas gerações.

Sucintamente, baseando em Escobar (idem), mencionaremos a concepção de cultura para essa tendência e, portanto, a compreensão da cultura corporal, com os quais coadunamos: 
O aprofundamento na história leva a compreender que a atividade prática do homem, motivada pelos desafios da natureza, desde o erguer-se da posição quadrúpede até o refinamento do uso da sua mão, foi o motor da construção da sua materialidade corpórea e das habilidades que the permitiram transformar a natureza. Este agir sobre a natureza, para extrair dela sua subsistência, deu início à construção do mundo humano, do mundo da cultura. Por isso, "cultura" implica apreender o processo de transformação do mundo natural a partir dos modos históricos da existência real dos homens nas suas relações na sociedade e com a natureza. (idem, p. 93, itálicos nosso e no original, respectivamente).

Dado essa reflexão, a autora, assim como o Coletivo de Autores (1992), explicita que o resultado da construção social no âmbito da nossa corporeidade proporciona atualmente um patrimônio de atividades, cunhadas na expressão e na comunicação com sentidos e significados nas ações tanto no campo objetivo como no subjetivo dos indivíduos. O que concluímos sobre essa tendência é que a mesma possui afinidades quanto aos posicionamentos da pedagogia histórico-crítica, como nos afirma Loureiro (1996). No entanto, compreendemos que a tendência crítico-superadora carece ainda de um maior aprofundamento no que tange a definição do objeto de conhecimento da educação física escolar perante o ponto de vista subordinado ao modo de produção capitalista e na necessidade de uma reflexão e intervenção crítica sob esses elementos conservadores. Destarte, compreendemos que a pedagogia histórico-crítica avulta em possibilidades para o aprofundamento necessário para a intervenção pedagógica na educação física escolar sob a égide de uma postura crítica.

Reportando-nos a pedagogia histórico-crítica, explicitamos uma afirmação de Saviani (2012a, p. 160) em relação ao embasamento teórico dessa pedagogia: “(...) é tributária da concepção dialética, especificamente na versão do materialismo histórico, tendo afinidades, no que se refere às suas bases psicológicas, com a psicologia históricocultural desenvolvida pela Escola de Vigotski."

Compreendemos, sob influência da pedagogia histórico-crítica que a realidade social é síntese de múltiplas determinações que se assenta pelas relações de produções. A educação como processo inerente da relação social pode assumir, portanto, apenas dois posicionamentos antagônicos frente o atual modo de produção capitalista: 1) indo ao encontro do movimento social oriundo do modo de produção hodierno, ou seja, apresentando uma intervenção implícita ou explicitamente conservadora - como é o caso da tendência crítico-emancipatória; 2) ou indo de encontro com os atuais condicionantes que interferem as ações sociais em prol da desigualdade social, da expropriação do humano, da expropriação do conhecimento.

A pedagogia histórico-crítica busca atender os preceitos desse segundo posicionamento frente à realidade social.

A fundamentação teórica da pedagogia histórico-crítica nos aspectos filosóficos, históricos, econômicos e político-sociais propõe-se explicitamente a seguir as trilhas abertas pelas agudas investigações desenvolvidas por Marx sobre as condições históricas de produção da existência humana que resultaram na forma da sociedade atual dominada pelo capital. É, pois, no espírito de suas investigações que essa proposta pedagógica se inspira. (SAVIANI, 2012a, p. 160).

Portanto, estabelecido esse pressuposto, a pedagogia histórico-crítica parte do princípio de que “(...) o trabalho educativo é o ato de produzir, direta e intencionalmente, 
em cada indivíduo singular, a humanidade que é produzida histórica e coletivamente pelo conjunto dos homens." (SAVIANI, 2008, p. 13). A educação é compreendida como uma mediação da prática social global. Dessa forma, como Saviani (idem, p. 14) nos adverte: “(...) a escola diz respeito ao conhecimento elaborado e não ao conhecimento espontâneo; ao saber sistematizado e não ao saber fragmentado; à cultura erudita e não à cultura popular." A prática social global, portanto, é o ponto de partida e de chegada da educação, obviamente, partindo de uma ótica histórica e dialética dessa prática. E, assim, levando em consideração o conhecimento na sua forma mais elaborada. $\mathrm{O}$ método pedagógico que parte da prática social, concebe o docente e o aluno inseridos nessa prática social global. Saviani (2012b, p. 78-79) expõe que metodologicamente o movimento que busca auxiliar na compreensão da prática social no sentido de contribuir para um salto qualitativo nas apropriações realizadas pelos alunos no cerne da intervenção pedagógica deve atuar pelo

movimento que vai das observações empíricas ("o todo figurado na intuição") ao concreto ("uma rica totalidade de determinações e de relações numerosas") pela mediação do abstrato ("a análise, os conceitos e as determinações mais simples") constitui uma orientação segura tanto para o processo de descoberta de novos conhecimentos (o método científico) como para o processo de ensino (o método pedagógico).

Tais ações mencionadas têm que ser levadas em consideração e efetivadas no bojo das intervenções pedagógicas da educação física. Sendo assim, para finalizarmos a nossa exposição, mencionaremos os elementos do método pedagógico elucidados por Saviani (2008; 2009; 2012a) na sua formulação e proposição da pedagogia histórico-crítica. Esse método

parte da prática social em que o professor e aluno se encontram igualmente inseridos, ocupando, porém, posições distintas, condição para que travem um relação fecunda na compreensão e no encaminhamento da solução dos problemas postos pela prática social, cabendo aos momentos intermediários do método identificar as questões suscitadas pela prática social inicial (problematização), dispor os instrumentos teóricos e práticos para a sua compreensão e solução (instrumentação) e viabilizar sua incorporação como elementos integrantes da própria vida dos alunos (catarse). (SAVIANI, 2012a, p. 160).

Trata-se da compreensão do processo de ensino e aprendizagem levando em consideração os indivíduos concretos, síntese das relações sociais que se manifesta como uma unidade da diversidade. A condição expressada pela pedagogia histórico-crítica é colocar em evidência e como prioridade a "(...) efetivação da intencionalidade educativa condensada na conquista por parte de cada aluno singular 'da humanidade produzida pelo conjunto dos homens', isto é, pela prática social.” (MARTINS, 2013, p. 292). Por esse caminho metodológico encontra-se na quinta etapa do método pedagógico a "prática social" como ponto de chegada, que diz respeito ao final do processo que propôs ao aluno a apropriação de determinado conhecimento na sua forma mais elaborada e, partindo dessa etapa para uma nova ação, isto é, para uma prática social inicial, mas efetivado de uma maneira mais complexa com um nível maior da compreensão intelectual do aluno. "(...) os referidos passos superam em muito uma sequenciação didática, balizada metodologicamente a análise das funções sociais da educação escolar (...) e, também, dos aspectos didáticos da prática docente." (idem, p. 293). 
Dado essa condição de apropriação por parte do aluno, podemos concluir que a pedagogia histórico-crítica propõe a sua definição como o objetivo da educação - que colocamos também como objetivo da educação física escolar -: a identificação dos elementos culturais que se caracterizam como necessidade de serem assimilados por parte dos alunos, isto é, que tem uma relação direta e intensiva com os dados da realidade concreta e, sendo assim, necessitam apropriarem-se desses elementos culturais para que se tornem "humanos" ou seres sociais na sua máxima possibilidade, na sua formação omnilateral. Cabe, também, a educação escolar e, por conseguinte, a educação física escolar encontrar formas para que se possa chegar nesse objetivo ou nesse fim da educação e da educação física.

Isso nos remete mencionar, "sem sombras de dúvidas", que a educação física escolar deve dar enfoque no "(...) ensino sistematicamente orientado à transmissão dos conhecimentos científicos, tal como proposto pela pedagogia histórico-crítica, alia-se à formação dos comportamentos complexos culturalmente formados." (MARTINS, 2013, p. 314).

Nesse contexto, compreendemos que a intervenção da educação física escolar deve ocorrer por meio de uma orientação histórica e crítica, possibilitando por parte dos indivíduos inseridos nesse processo uma reflexão crítica perante o conhecimento produzido histórica e socialmente pela a humanidade no que tange a especificidade da educação física. Desse modo, há a possibilidade de superação da compreensão conservadora do objeto de conhecimento da educação física escolar, anexando-o como mais um dos elementos constituintes de um projeto histórico que perspective a transformação social.

\section{Considerações finais}

Ancorado nos pressupostos da pedagogia histórico-crítica, este trabalho objetivou colocar em evidencia alguns elementos que formulam a tendência crítico-emancipatória que, de maneira equivocada, tem como horizonte explanar um posicionamento crítico em relação ao objeto de conhecimento da educação física escolar no bojo dos atuais condicionantes sociais. Perante a argumentação dessa tendência, específica da educação física, explicitamos elementos que apresentaram incoerências na fundamentação utilizada pela tendência crítico-emancipatória na tentativa de compreender criticamente $\mathrm{o}$ movimento humano no seio das atuais ações sociais.

Concluímos, então, que a pedagogia histórico-crítico levando a cabo os pressupostos do materialismo histórico-dialético e da psicologia histórico-cultural contribui para uma análise crítica e de maneira totalizante da realidade concreta. Colocando como eixo da sua intervenção pedagógica uma condição político-social que atue de maneira histórica, dialética, crítica e progressista dentro do atual modo de produção que tem a exploração do homem sobre o homem como sua principal sustentação. Agindo, então, de maneira que perspective a formação humana de maneira omnilateral. Para que isso ocorra efetivamente temos que ter como embasamento elementos concretos que contribuam para as determinações de um projeto histórico e superador.

A organização pedagógica, portanto, para a educação física escolar tem que ter a mesma diretriz do que supracitamos. Então, propomos para a educação física escolar uma reflexão tendo como alicerce o aporte teórico da pedagogia histórico-crítica, pois, assim terá subsídio para interferir criticamente sobre o seu objeto de conhecimento, elencando o mesmo como mais um elemento que possui possibilidades de contribuição para a transformação social. 


\section{Referências}

ABBAGNANO, N. Dicionário de filosofia. 5. ed. São Paulo: Martins Fontes, 2007.

ALVES, G. L. A produção da escola pública contemporânea. 4. ed. Campinas: Autores Associados, 2006.

ARAÚJO, L. C. G. et al. Ontologia do movimento humano: uma teoria do "semovimentar" humano. Revista Pensar a Prática, Goiânia, v. 13, n. 03, p. 1-12, set./dez. 2010 .

BRACHT, V. Educação física \& ciência: cenas de um casamento (in)feliz. 3. ed. Ijuí: Unijuí, 2007.

COLETIVO DE AUTORES. Metodologia do ensino de educação física. São Paulo: Cortez, 1992.

ESCOBAR, M. O. Cultura corporal na escola: tarefas da educação física. Revista Motrivivência, Florianópolis, ano VII, n. 08, p. 93-102, dez. 1995.

KOSIK, K. Dialética do concreto. 2. ed. 8. reimpr. Rio de Janeiro: Paz e Terra, 2010.

KUNZ, E. Kinein: o movimento humano como tema. Revista Kinein, Florianópolis, v. 01, n. 01, p. 01-06, dez. 2000.

Educação física: ensino \& mudanças. 3. ed. Ijuí: Unijuí, 2004.

Pedagogia do esporte, do movimento humano ou da educação física?. In: KUNZ,

E.; TREBELS, A. (Orgs.). Educação física crítico-emancipatória: com uma perspectiva da pedagogia alemã do esporte. Ijuí: Unijuí, 2006a. p. 11-22.

Transformação didático-pedagógica do esporte. 7. ed. Ijuí: Unijuí, 2006 b.

LOUREIRO, R. Pedagogia histórico-crítica e educação física: a relação entre teoria e prática. 1996. 238f. Dissertação de Mestrado (Mestrado em Educação). Programa de PósGraduação em Educação da Universidade Metodista de Piracicaba, Piracicaba, 1996.

MARTINS, L. M. O desenvolvimento do psiquismo e a educação escolar: contribuições à luz da psicologia histórico-cultural e da pedagogia histórico-crítica. Campinas: Autores Associados, 2013.

ORTIGARA, V. BERNARDO SILVA, M. Formação humana, educação e educação física. In: V Encontro Brasileiro de Educação e Marxismo: Marxismo, Educação e Emancipação Humana, 2011, Florianópolis. Anais... Florianópolis: V EBEM, 2011.

SAVIANI, D. Pedagogia histórico-crítica: primeiras aproximações. 10. ed. Campinas: Autores Associados, 2008. 
Escola e democracia: teorias da educação, curvatura da vara, onze teses sobre a educação política. 41. ed. Campinas: Autores Associados, 2009. 2012a.

A pedagogia no Brasil: história e teoria. 2. ed. Campinas: Autores Associados,

Marxismo, educação e pedagogia. In: SAVIANI, D.; DUARTE, N. (Orgs.). Pedagogia histórico-crítica e luta de classes na educação escolar. Campinas: Autores Associados, 2012b. p. 59-86.

TREBELS, A. H. A concepção dialógica do movimento humano: uma teoria do "semovimentar". In: KUNZ, E.; TREBELS, A. (Orgs.). Educação física críticoemancipatória: com uma perspectiva da pedagogia alemã do esporte. Ijuí: Unijuí, 2006. p. $23-48$.

TRIVIÑOS, A. N. S. Introdução à pesquisa em ciências sociais: a pesquisa qualitativa em educação. 1. ed. 18. rempr. São Paulo: Atlas, 2009.

\section{Notas}

\footnotetext{
${ }^{1} \mathrm{O}$ autor utiliza a sigla "EF" se referindo a "Educação Física".

${ }^{2}$ De acordo com o seu currículo Lattes, Kunz possui doutorado pelo Instituto de Ciências do Esporte pela Gottfried Wilhelm Leibniz Universität Hannover em 1987 e pós-doutorado pela mesma universidade em 1996. Atualmente é professor titular na Universidade Federal de Santa Catarina e membro do corpo editorial e revisor periódico de várias revistas científicas específicas da educação física. Possui experiência na área de educação física, com ênfase em Ciências do Esporte.

${ }^{3}$ Indicamos o texto de Trebels (2006), “A concepção dialógica do movimento humano: uma teoria do 'semovimentar", para explicitar com mais detalhes as abordagens dos autores holandeses supracitados em relação ao movimento humano.

${ }^{4}$ Andreas Trebels foi o orientador de Kunz da sua tese de doutorado realizada na Alemanha, na Universidade de Hannover. Trebels atua nas seguintes áreas: teorias do movimento humano, filosofia do esporte e da educação física e didática da educação física.
}

Recebido: novembro-13 Aprovado: março-14 